\title{
A RENDA DOS BENEFÍCIOS PREVIDENCIÁRIOS E A PROTEÇÃO SOCIAL DO TRABALHADOR
}

\author{
José Francisco Furlan Rocha*
}

\begin{abstract}
Sumário: 1. Dos mecanismos de proteção social; 2. O Nascimento da Previdência Social; 3. Da expansão dos mecanismos de proteção social: o surgimento da Seguridade Social; 4. Dos riscos profissionais às necessidades sociais; 5 . Da função dos mecanismos de proteção social; 6 . Da função da Previdência Social; 7. O modelo brasileiro de proteção social; 8. Do Regime Geral de Previdência Social; 9. Das prestações Previdenciárias e as necessidades protegidas; 10. Do cálculo dos benefícios previdenciários; 11. Do salário de contribuição; 12. Do salário de benefício; 13. Da renda mensal inicial do benefício; 14 . Da correlação entre a renda do segurado e a prestação ofertada; 15 . Da correção entre a necessidade social e a proteção ofertada; 16. Conclusão.
\end{abstract}

Resumo: No presente estudo procuramos identificar as funções dos benefícios previdenciários a partir de uma perspectiva histórica, bem como definir os elementos sobre os quais se amparam as prestações devidas pela Previdência Social no Brasil, especialmente a correlação existente entre a renda do benefício, a remuneração do trabalhador e a necessidade social objeto de proteção.

Palavras-chave: Previdência Social. Benefícios. Função. Renda. Proteção Social. Necessidades Sociais.

Abstract: In the present study we intend to identify the functions of social security benefits, from a historical perspective, as well as define the basis of benefits of Social Security in Brazil, especially the correlation between the income of the benefit, the salary of the worker and the necessities of the society.

Keywords: Social Security. Benefits. Function. Income. Social Protection. Social needs.

\section{Dos mecanismos de proteção social.}

O homem, ente supremo de tudo quanto existe no mundo, é, ironicamente, um ser extremamente vulnerável a sofrer toda classe de contingências durante o transcurso de sua existência ${ }^{1}$. Desde sempre os seres humanos estão sujeitos à enfermidades, falecimento, invalidez, falta de trabalho, idade avançada, etc, os quais dão lugar a estados de necessidade que em seu conjunto constituem uma insegurança social.

Segundo José Dávalos, os sistemas de proteção social são entendidos como as formas por meio das quais, através da utilização de recursos presentes, se garantirá um interesse futuro. Para citado autor, doutrinariamente se classificam em: sistemas individuais (poupança), sistemas coletivos (mutualidade e seguro privado) e sistema social duplo (contratação coletiva e proteção social em sentido estrito) ${ }^{2}$.

\footnotetext{
* Procurador Federal junto a PFE-INSS de São Carlos, bacharel em direito pela UNESP - Franca/SP, mestrando em direito previdenciário pela PUC/SP.

${ }^{1}$ DÁVALOS, José. La Crisis de Los Sistemas de Seguridad Social. P.923

${ }^{2}$ DÁVALOS, José. La Crisis de los Sistemas Contemporâneos de Seguridad Social. P. 920.
}

Revista de Estudos Jurídicos, a. 15, n. 22, 2011 
A compreensão dos mecanismos de proteção social está conectada à noção de riscos sociais, ou, ainda, contingências e necessidades sociais, expressões que podem ser analisadas a partir de duas perspectivas: uma objetiva, que qualifica os riscos/necessidades como sociais pelo fato de atingirem qualquer indivíduo e serem inerentes à vida em sociedade; e outra, subjetiva, por se tratar de riscos/necessidades cuja prevenção só a coletividade tem condições de organizar e cujos danos só ela pode promover a reparação, pois os indivíduos, isoladamente, não tem meios técnicos ou econômicos para lhes fazer frente ${ }^{3}$.

A perspectiva objetiva constitui o fundamento de criação das primeiras técnicas de proteção do ser humano em face de problemas que podem atingir qualquer pessoa. Constituem exemplos clássicos destas técnicas primárias de proteção a assistência, a poupança, a caridade, o mutualismo e os seguros privados. Estas técnicas não deixaram de existir e, ainda hoje coexistem ao lado de outros mecanismos mais abrangentes de proteção; porém, são limitadas, facultativas e, muitas vezes, inacessíveis para a parcela mais carente da população.

A perspectiva subjetiva de proteção social e de consciência do risco social, em que a própria coletividade passa a estar encarregada da prevenção e reparação dos danos advindos dos riscos sociais, tem início e é fortalecida após a instauração do processo capitalista de produção, fruto das Revoluções Industriais e Burguesa ${ }^{4}$.

A passagem para um modelo de proteção em face dos riscos sociais baseada na solidariedade teve uma evolução lenta e praticamente não avançou entre o século XVIII e o final do século XIX. Neste período, o Estado liberal capitalista se caracteriza essencialmente pela idéia de liberdade e pelo mais puro modelo abstencionista, baseado no princípio do Laissez faire, laissez passer, expressão-símbolo do liberalismo econômico.

Segundo José Dávalos,

En virtud del individualismo y liberalismo (...) el derecho del trabajo y de la prevision social era un imposible, condicion que se generalizó a todos los Estados europeos; y si bien contenia el oferecimento de ciertas medidas de prevision social, nunce se cumplieron, con la sola excepcion de las normas protectoras de la infancia. ${ }^{5}$

Apenas no final do século XIX e principalmente no século XX foram propostos e implantados sistemas de proteção social em que a própria coletividade estava encarregada pela prevenção e reparação dos danos advindos dos riscos sociais, sistemas que foram denominados seguros sociais. $\mathrm{O}$ marco inicial desta nova fase, bem como do próprio Direito Previdenciário, foram as Leis editadas por Otto Von Bismarck no antigo Estado da Prússia (atual Alemanha).

\footnotetext{
${ }^{3}$ KONKEL Júnior. Nicolau. Contribuições Sociais. São Paulo: Quartier Latin, 2005, p.30.

${ }^{4}$ KONKEL Júnior. Nicolau. Contribuições Sociais. São Paulo: Quartier Latin, 2005. p.32.

${ }^{5}$ DÁ VALOS, José. La Crisis de Los Sistemas de Seguridad Social. P.925.
} 


\section{O Nascimento da Previdência Social.}

As leis aprovadas entre 1883-1889 no Estado alemão representaram a primeira intervenção formal do Estado em prol da instituição de programas sociais destinados aos trabalhadores. Diferentemente das técnicas até então utilizadas, que tinham como características comuns a voluntariedade e uma abrangência limitada, a previdência social surge como um mecanismo de proteção obrigatório, com presença marcante do Estado, voltado à reduzir ou suprimir as necessidades sociais dos trabalhadores.

\section{Segundo Almansa Pastor,}

"la prevision social constituye un conjunto de medidas o instrumentos protectores de necesidades sociales que el Estado pone a disposicion de, o impone a, los individuos para atender las necesidades sociales de éstos, con la finalidad de cumplir la funcion estatal de liberar a los individuos de las necesidades sociales ${ }^{6}$."

José Dávalos afirma ainda que

"la prevision social supone un ilimitado número de posibilidades de que sucedan acontecimentos inciertos que generen necesidad; asimismo, supone una selección de los medios requeridos para afrontar las consecuencias de tales eventos.",

O modelo idealizado por Bismarck e incorporado ao sistema jurídico da Prússia foi um dos mais difundidos pelo mundo e, em síntese, caracteriza-se pela: (i) adoção da técnica do seguro privado, (ii) filiação obrigatória, (iii) financiamento com base em contribuições dos trabalhadores, empregadores e Estado; (iv) proteção contra os riscos profissionais; (v) benefícios destinados aos trabalhadores e seus dependentes; e (vi) prestações de caráter indenizatório, substitutivas do salário, caracterizadas como direito subjetivo público do segurado.

\section{Segundo José Dávalos,}

"la prevision social se identifica com o principio humanístico de quien entrega a la economia todo cuanto la naturaliza le ha dado (su fuerza de trabajo), tiene em reciprocidad el derecho de recibir todo cuanto la naturaliza le exige para poder vivir como persona humana, lo mismo en el presente que en el futuro.",

${ }^{6}$ ALMANSA PASTOR, José Manuel. Derecho de la seguridade social, Madrid, V I, Editora Tecnos, 1977, p.43.

${ }^{7}$ DÁVALOS, José. La Crisis de Los Sistemas Contemporâneos de Seguridad Social. P.920.

${ }^{8}$ DÁVALOS, José. La Crisis de Los Sistemas Contemporâneos de Seguridad Social. p.921. Para o autor, o vínculo indissociável entre o direito do trabalhador e a previdência social se torna mais sólido se considerarmos que os direitos à previdência social são uma consequência da vida dedicada ao trabalho. 
Conforme Fábio Z. Ibrahim, os projetos de Bismarck foram a gênese da proteção garantida pelo Estado, funcionando este como arrecadador de contribuições exigidas compulsoriamente dos participantes do sistema. Para o autor, os elementos que nos permite caracterizar o sistema de seguros sociais previdenciários são a contributividade e a compulsoriedade de filiação 9 .

Daniel Machado da Rocha aponta, ainda, que o princípio portador das diretrizes essenciais do direito previdenciário é o da solidariedade, o qual se constitui no seu eixo axiológico, podendo ser nominado de princípio estruturante dos sistemas previdenciários. Para o autor, este princípio revelase apto a catalisar a articulação entre o Estado e a sociedade, operando como verdadeira bússola condutora da nau da previdência social no revoltoso mar das necessidades sociais ${ }^{10}$.

$\mathrm{O}$ arquétipo do seguro social proposto por Bismarck era semelhante ao seguro privado, combinado com as experiências de técnicas mutualistas, tendo como diferencial os dois elementos acima citados (contributividade e compulsoriedade), além da presença Estatal, que inicialmente atuava de forma indireta, tão somente para garantir o pagamento das contribuições e efetivar a obrigatoriedade desta contribuição. Os segurados, por outro lado, se limitavam aos trabalhadores. Sua essência era muito próxima do seguro privado.

Segundo Heloísa Derzi, a finalidade dos seguros de pessoas está voltada à previdência; destina-se a resguardar o segurado de eventos que possam causar onus para si ou para terceiro prejudicado com sua morte ou enfermidade. Pode, ainda, ter a finalidade de poupança, garantindo futuro seu ou de terceiro ${ }^{11}$.

O Seguro Social surge, portanto, com uma formatação próxima à dos seguros privados, mas desde sua origem cumpria a função social de propiciar aos trabalhadores um sistema de proteção diante das dificuldades naturais da vida mediante contribuição compatível com os ganhos do trabalhador.

Após as leis de Bismarck, cerne do que conhecemos como seguro social, e marco inicial do Direito Previdenciário, encontramos inúmeros diplomas legais e documentos com finalidade de proteção social dos trabalhadores.

No fim do século XIX e início do século XX são editadas diversas Leis na Inglaterra instituindo o seguro obrigatório contra acidentes de trabalho (Workman's Compensation Act, 1897), a pensão aos maiores de 70 anos, independentemente de contribuição (Old Age Pensions, 1908) e, por fim, um sistema de Previdência Social, de caráter obrigatório e sustentado através de contribuições do empregador, trabalhador e do Estado (National Insurance Act, 1911).

9 IBRAHIM, Fábio Zambitte. Curso de Direito Previdenciário. $11^{\mathrm{a}}$ Ed. Niterói: Impetus, 2008, p.40.

${ }^{10}$ ROCHA, Daniel Machado da. O direito Fundamental à Previdência Social. Porto Alegre: Livraria do Advogado, 2004. P. 127.

${ }^{11}$ DERZI, Heloisa Hernandez. Os benefícios da pensão por morte: regime geral de previdência social. São Paulo: Lex Editora, 2004, p.42. 
$\mathrm{O}$ início do século XX foi marcado pela fase de constitucionalização dos direitos sociais dos trabalhadores, com a inserção nos textos constitucionais de diversos países de direitos e garantias dos trabalhadores e das pessoas necessitadas, bem como de programas destinados a fomentar esta proteção social.

\section{Da expansão dos mecanismos de proteção social: o surgimento da Seguridade Social.}

No período da Segunda Guerra Mundial, e principalmente após 1945 observa-se um grande avanço nas políticas públicas voltadas ao atendimento da população, com uma crescente preocupação do Estado na universalização de direitos sociais, que até então ficavam limitados, em sua maioria, à classe trabalhadora. Esta fase, conhecida como o período de expansão dos modelos de proteção social, está conectada a disseminação das idéias de John Maynard Keynes, que pregava o crescimento econômico num contexto de intervenção estatal no sentido de melhor distribuir a renda nacional.

Segundo José A. Savaris

A preocupação da atuação estatal passava a centrar-se na abolição do estado de necessidade e a garantia a todo cidadão de uma renda suficiente que lhe permitisse subsistir e prover a subsistência de sua família e, ao mesmo tempo, na efetivação de medidas de prevenção de certos riscos sociais, ordenadas pela política de pleno emprego e de saúde. ${ }^{12}$

A ideia de Seguridade Social encontrou sua máxima expressão no Informe Beveridge, modelo de proteção integral da população que surge com a política implantada na Inglaterra, a partir de 1942, pelo Lorde inglês William Henry Beveridge (1879-1963), que tratou da reorganização e universalização do sistema de proteção social nas áreas de seguro social, assistência social e saúde.

Surgia, assim, o regime Beveridgeano ou de repartição, em que toda a sociedade contribui para a criação de um fundo previdenciário, do qual são retiradas as prestações para aqueles que venham a ser atingidos por algum dos eventos previstos na legislação de amparo social. ${ }^{13}$

Em síntese, o relatório apresentou recomendações ao governo inglês com o fim de reformular os mecanismos de proteção da população, destacandose: a) proteção de toda a população da totalidade dos riscos sociais, b) prestações em valor uniforme, que corresponda ao suprimento das necessidades vitais, c) financiamento através de contribuições no que tange às prestações em geral, e impostos, no que diz respeito aos abonos de família e ao tratamento de saúde, d) gestão confiada ao serviço público, e) complemento das medidas por

${ }^{12}$ Curso de Especialização em Direito Previdenciário. Coord: Daniel Machado da Rocha e José Antonio Savaris. Curitiba: Juruá, 2008. p. 102.

${ }^{13}$ CASTRO, Carlos Alberto Pereira; LAZZARI, João Batista. Manual de Direito Previdenciário. $8^{\mathrm{a}}$ ed. Florianópolis: Conceito Editorial, 2007. p. 40. 
meio de política do pleno emprego e política sanitária e de saúde, com atendimento gratuito a toda a população.

Dentro desta nova concepção de proteção social, os elementos riscoevento-dano passaram a buscar novos conceitos para a compatibilização com o novo modelo protetor, voltado para a proteção das necessidades sociais ${ }^{14}$.

\section{Dos riscos profissionais às necessidades sociais}

É inerente ao instituto do seguro social a ideia de risco, conceituado por Almansa Pastor como uma possibilidade de que aconteça um fato futuro, incerto e involuntário que produza dano com possível avaliação econômica ao segurado $^{15}$.

Assim, se observa na origem da Previdência Social uma nítida relação deste instrumento de proteção social com a noção de seguro, em que se paga uma prémio (definido por técnicas contábeis e atuariais) com a finalidade de proteção do trabalhador e seus dependentes em face de um evento futuro, incerto e imprevisível, como por exemplo, um acidente de trabalho, uma enfermidade ou o próprio óbito do segurado.

No entanto, em razão da evolução dos instrumentos de proteção social e da proteção ofertada, o conceito de risco social deixa de se harmonizar com o ideal de proteção da Previdência Social (e muito menos da Seguridade Social), tendo em vista a necessidade cada vez maior da proteção em face de eventos não necessariamente futuros, imprevisíveis ou involuntários, tais como a maternidade, a família, a idade avançada, o desemprego atual, entre outros.

Além disso, o aspecto danoso do risco no contexto previdenciário e securitário mostrou-se igualmente ultrapassado em função da proteção dispensada, por exemplo, à maternidade, à família e à educação de um filho, para o que é inadmissível o rótulo de prejuízo ou dano.

A prestação previdenciária, ao longo do tempo, passou a se relacionar não mais diretamente com o evento (acidente, enfermidade, morte, velhice, etc), mas com a consequência danosa advinda destes eventos, que se consubstancia em um estado de necessidade para o trabalhador e seus dependentes, normalmente em função da diminuição de seus ganhos ou incrementos de seus gastos.

Neste sentido, observa-se ao longo da história, especialmente com a noção de necessidade de proteção integral da sociedade pelo Estado, a substituição da expressão risco social pela noção de necessidades sociais, ou ainda, contingências sociais.

O que se socorre na previdência social e na Seguridade Social é sempre a necessidade social; não, portanto, a invalidez, a morte, a velhice, etc...

${ }^{14}$ DERZI, Heloisa Hernandez. Os benefícios da pensão por morte: regime geral de previdência social. São Paulo: Lex Editora, 2004, p.66.

15 ALMANSA PASTOR, José Manuel. Derecho de la seguridade social, Madrid, V I, Editora Tecnos, 1977, p. 220. 
consideradas em si mesmas, mas, sim, a repercussão que elas acarretam, o comprometimento da subsistência que as contingências ensejam ao privarem da renda ou sobrecarregarem as despesas dos sujeitos que vivem do próprio trabalho ou daqueles que deste dependa ${ }^{16}$.

No momento em que se constitucionalizam regras reconhecedoras das necessidades sociais como verdadeiro acervo histórico, moral, jurídico e cultural de um povo, conquistado ao longo de duros embates ideológicos através dos séculos, esse Estado não apenas se torna guardião dos direitos sociais como assume o dever de agir no sentido de viabilizar os meios idôneos de superá-las ${ }^{17}$.

Mattia Persiani leciona que

"A eliminação das situações de necessidade, como qualquer outra, não
pode ser concretizada por indivíduos que são seus titulares, mas deve ser
garantida por toda a coletividade organizada no Estado, para a qual,
portanto, essa libertação constitui fim a ser visado, recorrendo-se a uma
solidariedade que é geral, na medida em que envolve todos os cidadãos."18

Com este objetivo, principalmente a partir do modelo de Seguridade Social proposto por Beveridge, deixa-se de trabalhar com a ideia de proteção em face de riscos sociais passando-se a proteger as chamadas necessidades sociais.

\section{Da função dos mecanismos de proteção social.}

Em linhas gerais, nos regimes baseados no modelo idealizado por Bismarck os beneficiários são, antes de tudo, os trabalhadores assalariados; o custeio é feito através de contribuições de que participam os trabalhadores, tomando-se como referência o salário auferido, sobre o qual recai percentagem predeterminada e fixa e; a natureza das prestações é, predominantemente, indenizatória, visando compensar o beneficiário pelos prejuízos econômicos sofridos em virtude da inatividade ou da redução de sua capacidade de trabalho ${ }^{19}$.

Nestes sistemas de Previdência Social, a preocupação maior está voltada para a reparação objetiva do risco verificado através do sinistro, não sendo seu papel, histórico ou científico, a distribuição de renda.

Segundo Wladimir Novaes Martinez ${ }^{20}$, em virtude de sua razão de ser (prestações), a Previdência Social posta-se no lugar dos ingressos da pessoa,

16 PULINO, Daniel. A aposentadoria por invalidez no direito positivo brasileiro. São Paulo: Ltr. P.40/41.

${ }^{17}$ DERZI, Heloisa Hernandez. Os benefícios da pensão por morte: regime geral de previdência social. São Paulo: Lex Editora, 2004, p.72.

18 PERSIANI, Mattia. Direito da Previdência Social. São Paulo: Quartier Latin, 2009. p. 32.

19 RUSSOMANO, Mozart Victor. Curso de Previdência Social. 2 ${ }^{\mathrm{a}}$ Ed. Rio de Janeiro: Forense,1983.p 21.

${ }^{20}$ MARTINEZ, Wladimir Novaes. Curso de Direito Previdenciário, Tomo II, $2^{\text {a }}$ Ed. São Paulo: Ltr, 2003, p. 105. 
principalmente de quem vivia às custas do trabalho subordinado ou independente. Seu objetivo, portanto, é substituir tais meios quando o segurado não pode obtê-los através do labor.

Na Seguridade Social, segundo Mozart V. Russomano, aumentam de importância os programas de prevenção de enfermidades ou acidentes, bem como programas de assistência médica preventiva, para prolongar os índices etários de sobrevivência da população e evitar enfermidades ${ }^{21}$.

O modelo de Beveridge tentou conduzir a legislação britânica ao reconhecimento do dever social de libertar o homem de todas as necessidades existenciais, mediante métodos políticos e econômicos que permitissem a melhor, mais ampla, mais justa e mais humana distribuição de renda.

Segundo Mozart Russomano ${ }^{22}$, as finalidades da Seguridade Social são múltiplas e, dentre elas enumera a) a proteção de todos os cidadãos que, por suas condições econômicas ou físicas, careçam de proteção e amparo; b) a inexistência de contributividade direta, fixando suas prestações sem levar em conta o nível das contribuições pagas pelo segurado, e sim avaliando as necessidades mínimas da pessoa favorecida.

Nesta perspectiva, os benefícios da seguridade social idealizada por Beveridge não são apenas destinados aos trabalhadores, mas à população necessitada. Seus direitos não decorrem da condição de trabalhadores ou contribuintes, mas do fato de serem cidadãos. O custeio neste sistema abandona o critério do salário efetivamente recebido, para adotar um sistema de cotas fixadas dentro da capacidade contributiva de cada pessoa. As prestações, neste modelo, perdem seu caráter indenizatório e substitutivo e assumem um papel de integração do homem na vida comunitária, através de garantia de um padrão mínimo de vida para os que necessitem, tendo, ainda, uma forte função distributiva de renda e garantidora de um mínimo existencial.

Portanto, da análise destes dois modelos clássicos de proteção social, o modelo bismarckiano de Seguros Sociais e o modelo beveridgeano de Seguridade Social, observa-se funções distintas de atuação. O primeiro, o modelo de Seguro Social, possui prestações substitutivas dos rendimentos, porém limitado aos trabalhadores e seus dependentes. A Seguridade Social, por outro lado, visa essencialmente propiciar uma tutela de base para toda população através de ações nas áreas de saúde, assistência social e seguro social, tendo por fim a garantia de um mínimo de dignidade, através de benefícios, com natureza não substitutiva, e serviços destinados a toda a população.

${ }^{21}$ RUSSOMANO, Mozart Victor. Curso de Previdência Social. $2^{\mathrm{a}}$ Ed. Rio de Janeiro:Forense, 1983.p 56.

${ }^{22}$ RUSSOMANO, Mozart Victor. Curso de Previdência Social. $2^{\text {a }}$ Ed. Rio de Janeiro: Forense, 1983. p 55. 


\section{Da função da Previdência Social.}

A Previdência Social, seja como um instrumento autônomo (modelo bismarkiano), seja como parte integrante da Seguridade Social (modelo Beveridgeano), visa proteger os trabalhadores e seus dependentes de necessidades sociais, especialmente aquelas inerentes ao trabalho, através de benefícios pecuniários e serviços. Para a compreensão da função específica de seus benefícios (se substitutiva, redistributiva, indenizatória ou garantidora do mínimo existencial), no entanto, precisamos ir além, ingressando no regramento dado ao instituto em cada país.

A natureza e função específica das prestações dos diversos modelos de Previdência Social existentes no mundo, seja como sistema autônomo, seja como parte integrante da Seguridade Social, não possuem uma concepção comum em todos os ordenamentos jurídicos, oscilando, de Estado para Estado, em razão de questões políticas, econômicas, sociais e culturais.

Não queremos dizer com isto que os propósitos da Previdência Social se alterem significativamente de nação para nação. Há um núcleo comum, uma concepção básica universal inerente a todo conjunto de instrumentos de proteção social designados como Previdência Social.

Este núcleo é composto pelas ideias de solidariedade social, intervenção estatal, obrigatoriedade de filiação e proteção face às necessidades sociais que, direta ou indiretamente, são derivadas da redução ou impossibilidade de exercício de atividades laborais pelo segurado.

No entanto, para além desta definição básica, somente através do estudo do sistema jurídico de cada Estado é possível formularmos uma conceituação completa da Previdência Social e definirmos se determinado ordenamento jurídico apresenta um regime voltado para a substituição da renda do trabalhador ou tão somente garantia de um mínimo existencial.

Esta abordagem, como exposto, somente é possível quando saímos de uma análise teórica do direito previdenciário e ingressamos nos estudos do ordenamento jurídico de cada Estado.

Assim, a conceituação, o estudo e a análise da finalidade da Previdência Social (enquanto subsistema da Seguridade Social) no Brasil demanda uma junção das características essenciais acima expostas com as peculiaridades previstas no texto constitucional pátrio e legislação vigente.

Desta forma, o estudo da função específica de cada benefício ofertado pela Previdência Social brasileira passa necessariamente pela análise do sistema jurídico brasileiro.

\section{O modelo brasileiro de proteção social.}

A Constituição Federal de 1988 elevou a Previdência Social à condição de Direito Social, expressamente previsto no artigo $6^{\circ}$ da Constituição. Além disso, instituiu em nosso sistema a Seguridade Social, expressamente prevista 
no artigo 194 como um conjunto integrado de ações do poder público e da sociedade destinadas a assegurar os direitos relativos à saúde, previdência social e assistência social.

A seguridade social é a fase mais recente e avançada dentro do conceito de proteção social. Wagner Balera ${ }^{23}$ afirma que o Sistema Nacional de Seguridade Social, do ponto de vista sistemático, visa a implementação do ideal estágio de bem-estar e justiças sociais.

No mesmo sentido, Miguel Horvath Jr. aponta que

a seguridade social como política social é método de economia coletiva. Sendo método de economia coletiva, a comunidade é chamada a fazer um pacto técnico-econômico em que a solidariedade social é o fiel da balança. $^{24}$

Para José Antônio Savaris,

a seguridade social, concebida como um sistema de prevenção e de reparação das consequências de diversos acontecimentos qualificados como riscos sociais, surge ao termo de uma longa evolução de esforços políticos e de diversas técnicas de que se valeram os trabalhadores e o Estado para garantirem meios de subsistência na ocorrência de determinadas contingências, propiciando rendimentos de substituição das rendas que normalmente decorreriam do exercício da atividade profissional, ou serviços e valores de complementação, para tratamento de saúde e cobertura de encargos familiares. ${ }^{25}$

Para a consecução de suas finalidades, a Seguridade Social priorizou três áreas de atuação, que juntas, são capazes de propiciar um mínimo de dignidade humana e bem-estar social, ao garantir uma renda mínima aos necessitados, mecanismos reparadores para a classe trabalhadora no caso de necessidades sociais, bem como saúde toda a população.

Observa-se que há um cerne, um elemento que conecta estas três esferas de atuação e constituem o objetivo final da seguridade social, que é a dignidade da pessoa humana. Esta é a força motriz do sistema, apta a justificar seu existir e a impulsionar seus movimentos sincrônicos.

Analisada sob um ponto de vista sistemático, a dignidade, objetivo final da Seguridade Social, se entrelaça com outros preceitos e princípios constitucionais, atingindo uma perspectiva peculiar. O primeiro destes preceitos constitucionais que permeiam e amoldam a dignidade é o primado do trabalho.

O trabalho constitui um dos fundamentos da República Federativa do Brasil (artigo $1^{\circ}$, inciso IV, CF), sendo ainda considerado um direito social

${ }^{23}$ BALERA, Wagner. Sistema de Seguridade Social. $3^{\text {a }}$ ed. São Paulo: LTr, 2003. p.11.

${ }^{24}$ HORVATH JUNIOR, Miguel. Direito Previdenciário. $7^{\mathrm{a}}$ ed. São Paulo: Quartier Latin, 2008. p. 103.

${ }^{25}$ ROCHA, Daniel Machado da (Coord.) Curso de Especialização em Direito Previdenciário Volume I, $1^{\text {a }}$ ed., $4^{\text {a }}$ tiragem. Curitiba: Juruá, 2008, p. 98. 
(artigo $6^{\circ}, \mathrm{CF}$ ) e a base da ordem social, cujos objetivos são o bem-estar e a justiça sociais (artigo 193, CF).

Nesta perspectiva, a busca da dignidade dentro da ordem social tem como objetivo, essencialmente, a conservação e implemento do trabalho, observados os preceitos contidos na Constituição Federal. O trabalho corresponde a uma ferramenta de inclusão social, sendo um ponto chave para a compreensão do sistema de proteção social.

Analisando especificamente um dos subsistemas da Seguridade Social, a Previdência Social, Fábio Lopes V. Berbel aponta que

\begin{abstract}
o direito previdenciário gira em torno do trabalho. Todos os fatos jurídicos previdenciários, indistintamente, mantêm relação, direta ou indireta, com o fenômeno do trabalho. Isso se dá porque o objeto de proteção previdenciária é a perda da capacidade laboral que, pela presunção normativa, leva o indivíduo à indigência e, por conseguinte, à indignidade humana, pois, como advertia o Pontífice Leão XIII, o trabalho é o meio universal de prover às necessidades da vida, quer ele se exerça em terreno próprio, quer em alguma parte lucrativa cuja remuneração sai apenas dos produtos múltiplos da terra, com os quais ela se comuta... ${ }^{26}$
\end{abstract}

Além disso, em razão da solidariedade social, inerente ao modelo de proteção social adotado pela Constituição Federal de 1988, a dignidade da pessoa humana deixa de ser responsabilidade única do Estado, constituindo um objetivo de toda a sociedade brasileira.

Por esta razão, ao Estado e à sociedade, através da Seguridade Social, compete fomentar e implantar ações destinadas a suprir as necessidades sociais de ordem fisiológicas, familiares, profissionais e econômicas.

O sistema de Seguridade Social implantado pela Constituição Federal de 1988, apesar de uma nomenclatura semelhante à proposta pelo Plano Beveridge (Inglaterra, 1942), possui diferenças marcantes, agregando elementos dos modelos bismarckiano e beveridgeano, encontrando-se atualmente em um estágio de transformação.

Especificamente no campo de atuação da Previdência Social, não obstante a diversidade de modelos existentes, o arquétipo do modelo adotado no Brasil permanece com bases similares ao modelo originalmente proposto por Bismarck, e não à proposta de Beveridge.

Segundo Heloísa Derzi, a Previdência Social, que integra o Sistema de Seguridade Social, utiliza-se de técnicas próprias, as quais não podem abandonar suas exigências metodológicas, financeiras, jurídicas e administrativas. O modelo previdenciário, originalmente escolhido para a proteção dos trabalhadores, tem suas próprias regras e não pode ser confundido

${ }^{26}$ BERBEL, Fábio Lopes Vilela. Teoria Geral da Previdência Social.São Paulo: Quartier Latin,2005, p 117/118 
com outros modelos idealizados para proteger seletivamente os mais necessitados ${ }^{27}$.

Assim, a Previdência Social, não obstante integre a Seguridade Social e a auxilie na consecução de seus fins, com ela não se confunde. Esta, a Seguridade Social, tem por fundamento a universalidade de cobertura e atendimento, outorgando um mínimo de proteção social a toda a população indistintamente.

A Previdência Social, especialmente através do Regime Geral de Previdência Social, dentro do seu escopo constitucionalmente desenhado, tem limitada, no âmbito objetivo e principalmente subjetivo, a sua atuação.

Heloísa H. Derzi aponta que

Justamente para construir e ordenar o sistema de proteção social, o constituinte de 1988 optou por implantar o abrangente Sistema de Seguridade Social, no qual a Previdência Social é um subsistema destinado a cumprir o relevante papel de segurança econômica daqueles que exercem atividade laboral, dela retiram o seu sustento e, nas eventuais situações de impedimento de seu exercício, podem lançar mão de um mecanismo idealizado para abrandar os estados de necessidade possivelmente gerados pela inatividade ${ }^{28}$.

A Previdência Social, enquanto subsistema da Seguridade Social brasileira, possui contornos bem definidos a fim de, em conjunto com os demais subsistemas (assistência social e saúde), concretizar o ideal constitucional de proteção social universal.

A Previdência Social é o ramo de atuação estatal que visa a proteção de todo indivíduo ocupado numa atividade laborativa remunerada e de seus dependentes em face de necessidades sociais, advindas, em sua maioria, da perda ou redução, permanente ou temporária, das condições para obter o próprio sustento através do trabalho, através de um Regime público obrigatório destinado a amparar todos os trabalhadores e seus dependentes ${ }^{29}$.

\section{Do Regime Geral de Previdência Social.}

Previsto no artigo 201 da Constituição Federal, o Regime Geral de Previdência Social, de agora em diante chamado de Previdência Social, é um

${ }^{27}$ DERZI, Heloisa Hernandez. Os benefícios da pensão por morte: regime geral de previdência social. São Paulo: Lex Editora, 2004, p.127/128.

${ }^{28}$ DERZI, Heloisa Hernandez. Os benefícios da pensão por morte: regime geral de previdência social. São Paulo: Lex Editora, 2004, p.125.

29 Atualmente a Constituição Federal aponta 3 (três) regimes distintos de Previdência: a) um regime geral público e obrigatório, destinado á proteção dos trabalhadores e demais segurados em geral (artigo 201, CF); b) um regime público e obrigatório destinado aos servidores públicos civis e militares (artigo 40, CF); e c) um regime privado, facultativo, destinado a atuar de forma complementar aos demais sistemas (artigo 202 da CF). No presente estudo nos limitaremos à análise do Regime Geral de Previdência Social. 
regime público obrigatório destinado a todos os trabalhadores e possui caráter contributivo, tendo por fim o atendimento dos eventos previstos no texto constitucional e outros eleitos pelo legislador infraconstitucional. $\mathrm{O}$ artigo $1^{\circ} \mathrm{da}$ Lei ${ }^{\circ} 8.213 / 91$ dispõe:

Art. $1^{\circ}$ A Previdência Social, mediante contribuição, tem por fim assegurar aos seus beneficiários meios indispensáveis de manutenção, por motivo de incapacidade, desemprego involuntário, idade avançada, tempo de serviço, encargos familiares e prisão ou morte daqueles de quem dependiam economicamente.

Atualmente, a Previdência Social tem seus objetivos bem definidos dentro do Sistema de Seguridade Social, cabendo a ela a substituição da renda do trabalhador quando este se encontrar em uma das situações previstas no artigo 201 da Constituição e outras eleitas pelo legislador ordinário como dignas de amparo.

A natureza substitutiva das prestações previdenciárias não está expressamente prevista no ordenamento jurídico nacional e, até o advento da Constituição Federal de 1988, o regramento dos benefícios previdenciários era delegado, em sua totalidade, ao legislador ordinário ou, até mesmo, ao poder executivo.

A partir de 1988, através de uma leitura sistemática da Constituição Federal, observa-se uma postura do constituinte no sentido constitucionalizar diversas regras de cálculo dos benefícios e garantir o caráter substitutivo dos benefícios concedidos pelo Regime Geral de Previdência Social ${ }^{30}$.

No âmbito infraconstitucional, após a promulgação da Constituição de 1988, além da adequação do texto legal aos preceitos contidos na Constituição, o legislador pouco inovou, permanecendo no sistema diversos mecanismos historicamente consagrados e difundidos no âmbito da Previdência Social, tais como o limite máximo dos salários de contribuição, do salário de benefício e da renda mensal inicial, a existência de coeficientes de cálculo que não refletiam integralmente a renda do trabalhador, etc.

Desta forma, para compreendermos a função específica que as prestações devidas pela Previdência Social possuem, necessário estudarmos a legislação infraconstitucional, tendo como objetivo relacionarmos a necessidade

30 Em nosso entendimento, a natureza substitutiva dos benefícios previdenciários encontra previsão implícita nos $\S \S 2^{\circ}, 4^{\circ}$ e 11 do artigo 201 da CF. Esta função substitutiva impressa no ordenamento jurídico pela Constituição Federal de 1988 fica comprovada pelo artigo 58 do $\mathrm{ADCT}^{30}$, que restabeleceu o poder aquisitivo dos benefícios, mediante a indexação do valor dos benefícios concedidos antes da $\mathrm{CF} / 88$ ao correspondente número de salários mínimos quando de sua concessão. (Art. 58. Os benefícios de prestação continuada, mantidos pela previdência social na data da promulgação da Constituição, terão seus valores revistos, a fim de que seja restabelecido o poder aquisitivo, expresso em número de salários mínimos, que tinham na data de sua concessão, obedecendo-se a esse critério de atualização até a implantação do plano de custeio e benefícios referidos no artigo seguinte.) 
objeto de proteção com a prestação ofertada pelo sistema previdenciário, para podermos identificar a função de cada um dos benefícios previstos na legislação.

\section{Das prestações Previdenciárias e as necessidades protegidas.}

A legislação previdenciária atual estabelece na Constituição Federal e na Lei ${ }^{\circ}$ 8.213/91 uma série de prestações, que se subdividem em benefícios de natureza pecuniária e serviços. Em síntese, nos termos do artigo 18 da Lei $n^{\circ}$ 8.213/91 são ofertadas as seguintes prestações: I - quanto ao segurado: a) aposentadoria por invalidez; b) aposentadoria por idade; c) aposentadoria por tempo de contribuição; d) aposentadoria especial; e) auxílio-doença; f) saláriofamília; g) salário-maternidade; h) auxílio-acidente; II - quanto ao dependente: a) pensão por morte; b) auxílio-reclusão; III - quanto ao segurado e dependente:b) serviço social; c) reabilitação profissional.

Analisando os eventos jurídicos previstos nas normas que disciplinam a concessão de citados benefícios, observa-se, de acordo com a necessidade social protegida, uma convergência destas prestações para quatro situações específicas:

A primeira destas situações é a existência comprovada de uma incapacidade para o exercício de atividades laborais ou a impossibilidade de exercê-las. Este fato se expressa quando da análise dos pressupostos para a concessão da aposentadoria por invalidez e do auxílio-doença, que demandam a existência de uma incapacidade para o exercício de atividade que garanta a subsistência do segurado.

Dentro desta primeira categoria de benefícios, encontramos, ainda, aqueles benefícios destinados aos dependentes do segurado em caso de falecimento ou recolhimento à prisão, que garantem a estes beneficiários uma prestação em razão da impossibilidade de seu sustento pelo segurado.

O segundo grupo compõe-se dos benefícios que tem como fato gerador situações em que o legislador presume a existência de uma incapacidade ou a impossibilidade de trabalho e consequente subsistência do próprio segurado ou de um dependente.

Nesta classe de benefício se inserem: a) a aposentadoria por idade, em que o legislador presume a existência de uma incapacidade para o exercício de atividades laborais; b) a aposentadoria especial, utilizada como mecanismo de limitação do exercício de atividades insalubres, protegendo, assim, a integridade física do segurado; e c) o salário-maternidade, benefício devido à segurada em razão do nascimento de filho ou adoção e, tendo como finalidade uma proteção integral da criança.

$\mathrm{Na}$ terceira classe de benefício encontramos a aposentadoria por tempo de contribuição (e a aposentadoria por tempo de serviço), benefício de caráter substitutivo da renda do trabalhador, porém desvinculado de da comprovação de 
qualquer necessidade social imediata. Neste sentido, a concessão do benefício fica limitada apenas à comprovação de um número mínimo de contribuições.

Por fim, encontramos os benefícios de natureza não substitutiva, que, em síntese, tem como função complementar a renda do segurado (saláriofamília) ou indenizá-lo em razão de determinado fato (auxílio-acidente).

Assim, encontramos no ordenamento 4 (quatro) classes de benefícios, assim classificadas em razão: a) de sua natureza substitutiva ou não e b) da necessidade social objeto de proteção. Desta forma temos:

a) Benefícios substitutivos concedidos em razão de comprovada limitação para o exercício de atividade laboral;

b) Benefícios substitutivos concedidos em razão de presunção legal de limitação para o exercício de atividade laboral;

c) Benefícios substitutivos sem necessidade de comprovação de limitação para o exercício de atividades laborais;

d) Benefícios não substitutivos.

Uma vez feito esta classificação dos benefícios de acordo com a necessidade social objeto de proteção, passemos ao estudo do regramento legal quanto ao cálculo do valor dos benefícios previdenciários.

\section{Do cálculo dos benefícios previdenciários.}

A disciplina "do cálculo dos benefícios previdenciários" encontra seus fundamentos na Constituição Federal e suas principais regras estão inseridas nas Leis $n^{\circ}$ 8.212/91, 8.213/91 e 9.876/99.

O cálculo da renda dos benefícios previdenciários envolve o estudo de diversos institutos. Em síntese, a Renda Mensal Inicial - RMI historicamente foi apurada com base na aplicação de um percentual definido por lei (denominado coeficiente de cálculo do benefício) sobre o salário de benefício. Este, por sua vez, corresponde à média aritmética simples dos salários de contribuição existentes em um período básico de cálculo, devidamente atualizados de acordo com os critérios estabelecidos pela legislação.

Assim, partindo-se do valor dos salários de contribuição (remuneração do trabalhador) se chega ao valor dos benefícios previdenciários. Com isto, verifica-se uma expressão no valor do benefício de prestação continuada substitutivo dos rendimentos do segurado, a um só tempo, a participação do mesmo nos recursos destinados ao RGPS, bem como a equivalência do amparo previdenciário com o rendimento mensal a ser substituído.

Nesses termos, o salário de benefício é naturalmente a expressão de uma média dos salários de contribuição encontrados no período básico de 
cálculo (PBC) do segurado.

\section{Do salário de contribuição.}

O salário de contribuição é um instituto de natureza tributária e corresponde à base de cálculo para a apuração das contribuições sociais devidas pela empresa e pelos trabalhadores em geral. Nas palavras de Daniel Machado da Rocha e José Paulo Baltazar Junior, o salário-de-contribuição configura $o$ valor básico sobre o qual serão estipuladas as contribuições do segurado, ou na linguagem tributária, a base de cálculo da contribuição sobre a qual incidirão as alíquotas estabelecidas pela Lei de Custeio ${ }^{31}$.

A Constituição Federal de 1988 não se refere expressamente ao termo, mas estabelece no artigo 195, inciso I, como base de financiamento da seguridade social, as contribuições devidas pela empresa incidentes sobre " $a$ folha de salários e demais rendimentos do trabalho pago ou creditados, a qualquer título, à pessoa física que lhe preste serviço, mesmo sem vínculo empregatício."

Não obstante a natureza tributária do salário de contribuição (base de cálculo das contribuições sociais previdenciárias ${ }^{32}$ ), serve ele também de base para o cálculo dos benefícios devidos pela Previdência Social, adquirindo fundamental importância no estudo da renda dos benefícios previdenciários.

Esta dupla utilização do salário de contribuição, para fins de apuração da contribuição social devida, bem como o valor dos benefícios concedidos pelo Regime Geral de Previdência Social, corrobora a tese da natureza substitutiva dos benefícios previdenciários, tendo em vista a coincidência das bases de cálculo. Por outro lado, este fato gera, ao menos do ponto de vista empírico, uma presunção de sinalagmaticidade entre a relação jurídica de proteção e a relação jurídica de custeio, o que, juridicamente, não ocorre.

$\mathrm{O}$ instituto encontra-se regulamentado na pela Lei $\mathrm{n}^{\circ} 8.212 / 91$, que estabelece o plano de custeio do Sistema de Seguridade Social. O artigo 28 desta lei trabalha com quatro concepções de salário de contribuição, variando de acordo com o tipo de segurado que está envolvido na relação jurídica de custeio.

Para o segurado empregado e trabalhador avulso, o artigo 28, inciso I da Lei $n^{\circ} 8.213 / 91^{33}$, com redação dada pela lei $n^{\circ}$ 9.528/97, estabelece que o salário de contribuição corresponde à remuneração auferida em uma ou mais empresas por estes segurados.

${ }^{31}$ Comentários à Lei de Benefícios da Previdência Social, $7^{\mathrm{a}}$ ed. Porto Alegre: Livraria do Advogado, 2007.p.137

32 Assim entendida as contribuições sociais devidas pelos trabalhadores e pela empresa incidente sobre a folha de salários - artigo 195, inciso I, a e II da CF.

${ }^{33}$ Em sua redação original, o artigo 28, inciso I da Lei $n^{\circ} 8.213 / 91$ estabelecia que entende-se por salário de contribuição "a remuneração efetivamente recebida ou creditada a qualquer título, durante o mês em uma ou mais empresas, inclusive os ganhos habituais sob a forma de utilidades, ressalvado o disposto no $\S 8^{\circ}$ e respeitados os limites dos $\S \S 3^{\circ}, 4^{\circ}$ e $5^{\circ}$ deste artigo;" 
Para o empregado doméstico o salário de contribuição corresponde à remuneração registrada na Carteira de Trabalho e Previdência Social, conforme estabelece o artigo 28, inciso II da Lei $n^{\circ} 8.212 / 91$.

Para os contribuintes individuais, a legislação estabelece como salário de contribuição a remuneração auferida em uma ou mais empresas ou pelo exercício de atividade por conta própria, durante o mês.

No que se refere ao segurado facultativo, a legislação estabelece que o salário de contribuição corresponde ao valor declarado, observando-se também os limites estabelecidos pela legislação.

Para os chamados segurados especiais (agricultor, garimpeiro, pescador que exerçam atividades em regime de economia familiar), em razão do disposto no artigo $29 \S 6^{\circ}$ e artigo 39, inciso I, ambos da Lei $n^{\circ} 8.213 / 91$, não se utiliza o salário de contribuição para fins de cálculo do benefício, sendo a renda dos benefícios devidos a estes segurados correspondente a 1 (um) salário mínimo, ressalvada a hipótese de contribuição facultada no artigo 39,inc. II da Lei ${ }^{\circ} 8.213 / 91$.

O salário de contribuição, não obstante seja um reflexo da remuneração ou ganhos do trabalhador, possui limite mínimo e máximo.

O limite mínimo encontra previsão no artigo $28 \S 3^{\circ}$ da Lei $n^{\circ}$ $8.213 / 91$, e corresponde ao piso salarial, legal ou normativo, da categoria ou, inexistindo este, ao salário mínimo.

O limite máximo do salário de contribuição está expresso no artigo 28 $\S 5^{\circ}$ da Lei $n^{\circ} 8.212 / 91$ e, no nosso entendimento, se fundamenta no princípio constitucional da seletividade, um dos objetivos da seguridade social previsto no artigo 194 da CF. Há uma seleção, pelo legislador, das situações que merecem especial atenção da Previdência Social, na qual será propiciado proteção integral da renda (no caso previdenciário, esta proteção se dá entre estes limites mínimo e máximo). Para aqueles que estão acima deste limite, garante-se a contribuição com base no limite máximo estabelecido, com os respectivos reflexos no valor do benefício.

\section{Do salário de benefício.}

O salário de benefício corresponde à base de cálculo da maior parte dos benefícios previstos na legislação previdenciária. Seu valor é apurado através da média aritmética de determinados salários de contribuições, eleitos pelo legislador dentro de um período básico de cálculo e também se sujeita aos limites mínimos e máximos acima mencionados.

Segundo Wladimir Novaes Martinez ${ }^{34}$,

o salário de benefício é a importância apurada a partir dos salários de contribuição do segurado, sob a presunção de eles indicarem o nível da

\footnotetext{
${ }^{34}$ Comentários à Lei Básica da Previdência Social, tomo II, 4ª Ed. São Paulo: Ltr, 1997,p.190.
} 
fonte de subsistência do trabalhador, substituível pela prestação previdenciária.

A apuração deste valor envolve necessariamente:

1. a identificação do denominado período básico de cálculo (ou período contributivo), que corresponde ao lapso temporal em que são apurados os salários de contribuição que serão utilizados no cálculo do salário de benefício;

2. a identificação dos salários de contribuição existentes dentro deste lapso temporal,

3. a atualização destes valores até a data de início do benefício e,

4. a apuração da média aritmética dos salários de contribuição, nos termos previstos em lei.

Na legislação pátria, até o advento da Constituição Federal de 1988, os critérios de cálculo do salário de benefício eram definidos por lei, deixando-se, inclusive, de atualizar monetariamente determinadas parcelas integrantes do período básico de cálculo. Em 1988 houve a constitucionalização dos critérios de cálculo do benefício, estabelecendo-se, no caput do artigo 202 e $\S 3^{\circ}$ do artigo 201 da CF a garantia de cálculo com base na média dos 36 últimos salários de contribuição corrigidos monetariamente.

Destaca-se, ainda, a expressa previsão de irredutibilidade do valor dos benefícios, assegurando-se o seu reajustamento para preservar-lhes, em caráter permanente, o valor real, conforme critérios definidos em lei, bem como a incorporação de todos os ganhos habituais do segurado no cálculo de seu benefício.

Absorvendo os preceitos e princípios estabelecidos pela Constituição Federal de 1988, bem como adequando os critérios de cálculo e manutenção de benefícios às regras previstas na Constituição, foram editadas as Leis $n^{\circ}$ 8.212/91 e 8.213/91, tratando, respectivamente, do custeio da seguridade social e dos benefícios previdenciários.

A Emenda Constitucional $n^{\circ}$ 20/1998 deu nova redação a diversos dispositivos constitucionais, extinguiu a aposentadoria proporcional por tempo de serviço e desconstitucionalizou o critério de cálculo dos benefícios, o que possibilitou a alteração da sistemática de cálculo dos benefícios, concretizada pela Lei ${ }^{\circ}$ 9.876/99.

A edição da Lei $n^{\circ}$ 9.876/99, em sua essência, decorre das alterações introduzidas no ordenamento jurídico pela Emenda Constitucional no20/98 e seu objetivo foi integrar à sistemática de cálculo dos benefícios previdenciários o caráter contributivo e manter o equilíbrio financeiro e atuarial do regime. A renda inicial dos benefícios passou a ser obtida pela apuração da média de rendimentos do segurado com base nas contribuições vertidas em todo o seu período contributivo e foi introduzido no sistema o chamado fator previdenciário.

O fator previdenciário surgiu como alternativa à rejeição da inclusão do critério da idade mínima para a obtenção de todo e qualquer tipo de aposentadoria durante o processo de discussão da Reforma Previdenciária de 
1998. A idade não foi eleita como requisito de elegibilidade, mas sim um critério atuarial. Buscou-se com a introdução do fator previdenciário estabelecer uma relação direta entre tempo de contribuição, a idade e a expectativa de sobrevida, com o valor do benefício ${ }^{35}$.

Sob outra perspectiva, a Lei ${ }^{\circ}$ 9.876/99 trouxe para dentro do regime de previdência pública o principal elemento do sistema previdenciário privado: a lógica da capitalização. Manteve-se, no entanto, um modelo de repartição, baseado na lógica do pacto entre gerações.

A partir da entrada em vigor da Lei $\mathrm{n}^{\circ}$ 9.876/99 foram poucas e esparsas as alterações legislativas no âmbito do cálculo dos benefícios previdenciários, sendo mais sensíveis as alterações relativas às contribuições previdenciárias, com o intuito de possibilitar a inclusão de maior número de trabalhadores e pessoas que estavam afastadas do regime em razão do peso da carga tributária.

\section{Da renda mensal inicial do benefício.}

Uma vez definido o valor do salário de benefício, é possível fixar o valor da renda mensal do benefício previdenciário, apurada mediante a aplicação do coeficiente estabelecido por lei sobre o salário de benefício apurado. A definição da renda inicial tem como ponto de partida o estabelecimento da Data de Início do benefício - DIB, sendo, via de regra ${ }^{36}$, aplicado na sua apuração a legislação vigente nesta data.

Nos termos da Lei $\mathrm{n}^{\circ} 8.213 / 91$, com as alterações introduzidas pela Lei $\mathrm{n}^{\circ}$ 9.032/95 e Lei $\mathrm{n}^{\mathrm{0}}$ 9.876/99, o coeficiente de cálculo dos benefícios previdenciários é disciplinado nos seguintes termos:

\begin{tabular}{|c|c|c|c|}
\hline Benefício & Base de cálculo & Coeficiente & Acréscimos \\
\hline Auxílio-acidente & Salário de Benefício & $50 \%$ & - \\
\hline Auxílio-doença & Salário de Benefício & $91 \%$ & - \\
\hline $\begin{array}{c}\text { Aposentadoria por } \\
\text { invalidez }\end{array}$ & Salário de Benefício & $100 \%$ & - \\
\hline $\begin{array}{c}\text { Aposentadoria por } \\
\text { idade }\end{array}$ & Salário de Benefício & $70 \%$ & $\begin{array}{l}1 \% \text { para cada } 12 \\
\text { contribuições, } \\
\text { limitado a } 30 \% \text {. } \\
\text { Aplicação } \\
\text { facultativa do } \\
\text { Fator } \\
\text { Previdenciário. }\end{array}$ \\
\hline $\begin{array}{l}\text { Aposentadoria } \\
\text { Especial }\end{array}$ & Salário de Benefício & $100 \%$ & - \\
\hline $\begin{array}{l}\text { Aposentadoria por } \\
\text { tempo de contribuição }\end{array}$ & Salário de Benefício & $100 \%$ & $\begin{array}{l}\text { Aplicação } \\
\text { obrigatória do } \\
\text { fator } \\
\text { previdenciário }\end{array}$ \\
\hline
\end{tabular}

\footnotetext{
${ }^{35} \mathrm{O}$ fator se aplica apenas às aposentadorias por tempo de contribuição e por idade, sendo neste último caso, facultativa sua aplicação.

${ }^{36}$ Exceção deve ser feita às hipóteses de direito adquirido à regime jurídico anterior.
} 


\begin{tabular}{|c|c|c|c|}
\hline $\begin{array}{c}\text { Aposentadoria } \\
\text { professor }\end{array}$ & Salário de Benefício & $100 \%$ & $\begin{array}{l}\text { Aplicação } \\
\text { obrigatória do } \\
\text { fator } \\
\text { previdenciário }\end{array}$ \\
\hline
\end{tabular}
de remuneração variável

\begin{tabular}{|c|c|c|c|}
\hline Salário-família & \multicolumn{3}{|c|}{$\begin{array}{l}\text { Valor fixado pelo poder executivo, por filho, de acordo com renda do } \\
\text { segurado. }\end{array}$} \\
\hline $\begin{array}{c}\text { Auxílio-reclusão } \\
\text { (segurado de baixa } \\
\text { renda) }\end{array}$ & $\begin{array}{l}\text { Ap. Invalidez que o segurado } \\
\text { teria direito na data da reclusão }\end{array}$ & $100 \%$ & - \\
\hline Pensão por morte & $\begin{array}{l}\text { Ap. Invalidez que o segurado } \\
\text { teria direito na data do óbito ou } \\
\text { aquela que estava em gozo }\end{array}$ & $100 \%$ & - \\
\hline
\end{tabular}

Fonte: Lei $n^{0}$ 8.213/91 e Lei $n^{0}$ 9.032/95

Obs: Este quadro não se aplica ao segurado especial, ressalvado o disposto no artigo 39, II da Lei $n^{\circ} 8.213 / 91$.

Desta forma, a partir dos salários de contribuição identificados dentro do chamado período básico de cálculo (ou período contributivo, para aqueles que ingressaram após a lei $\mathrm{n}^{\circ}$ 9.876/99), apura-se o salário de benefício, sobre o qual se aplica o coeficiente estabelecido por lei, encontrando-se a renda mensal inicial dos benefícios mantidos pela Previdência Social.

\section{Da correlação entre a renda do segurado e a prestação ofertada.}

Após a análise do mecanismo de cálculo dos benefícios previdenciários, observa-se a existência de uma estreita relação entre a remuneração do segurado (que se reflete no salário de contribuição) e a apuração do benefício, o que nos demonstra que a sistemática de cálculo dos benefícios previdenciários busca, essencialmente, substituir a renda do trabalhador, adotando a sua média remuneratória como base de cálculo do benefício.

Uma das principais limitações existente hoje no sistema diz respeito à imposição de um limite máximo aos salários de contribuição, ao salário de benefício e à renda inicial. Este mecanismo não descaracteriza a natureza substitutiva das prestações previdenciárias, sendo esta limitação derivada do princípio constitucional da seletividade.

Por este princípio, o legislador infraconstitucional está autorizado a eleger as situações que merecem a proteção através da Previdência Social, nada impedindo-o de fixar, como o fez, limites mínimos e máximos de proteção. Assim, esta limitação não ofende o caráter substitutivo das prestações previdenciárias, mas apenas limita esta proteção a um determinado patamar.

Para aqueles que se enquadrem dentro dos limites estabelecidos presume-se a necessidade de proteção integral, nos casos e na forma da lei. Para aqueles que possuem rendimentos acima do limite estabelecido, o legislador 
garante a concessão do benefício, porém limitando-o ao patamar máximo que entende suficiente e adequado para a proteção do trabalhador ou de seus dependentes.

Assim, feito a ressalva quanto a existência de limite máximo para fins de concessão do benefício o que, no nosso entendimento, é plenamente compatível o sistema jurídico vigente, passemos à análise da correlação existente entre a necessidade objeto de proteção e o valor das prestações ofertadas.

\section{Da correção entre a necessidade social e a proteção ofertada.}

Além da correlação existente entre remuneração e salário de benefício, tratada no item anterior, analisando os critérios de cálculo dos benefícios vigentes observa-se uma estreita correlação entre o coeficiente de cálculo do benefício e a necessidade social protegida.

Assim, o cálculo dos benefícios previdenciários parte de dois pressupostos lógicos: a remuneração do segurado e a necessidade a ser amparada.

Neste sentido, observa-se que, quanto maior a necessidade social do trabalhador ou do dependente, maior será o coeficiente de cálculo, e, consequentemente, mais próximo será o valor do benefício à média da remuneração do segurado.

Para os benefícios considerados não substitutivos não se vislumbra esta paridade entre remuneração e o valor do benefício, em razão da própria natureza destas prestações, o que, inclusive, possibilita que sejam elas fixadas em valor inferior ao salário mínimo, não se sujeitando ao disposto no artigo 201 $\S 2^{\circ}$ da CF.

No que tange aos benefícios substitutivos da renda concedidos em razão de presunção absoluta de limitação para o exercício de atividade laboral (auxílio-doença, aposentadoria por invalidez, pensão por morte e auxílio-reclusão ${ }^{37}$ ), em razão do grau da necessidade a ser protegida, observa-se que o cálculo do benefício possibilita prestações que substituem integralmente a renda do trabalhador, ou um valor muito próximo a esta.

O mesmo ocorre com os benefícios substitutivos concedidos em razão de presunção legal de limitação para o exercício de atividade laboral (aposentadoria por idade ${ }^{38}$, o salário-maternidade e a aposentadoria especial).

\footnotetext{
${ }^{37}$ Em razão de expressa previsão no artigo 13 da Emenda Constitucional no 20/98, o auxílioreclusão é devido tão somente aos segurados considerados de baixa renda, sendo este dispositivo derivado do princípio da seletividade estabelecida pelo art. 194, III da CF.

${ }^{38} \mathrm{O}$ coeficiente de cálculo aplicado na aposentadoria especial é de $100 \%$ do salário de benefício e na aposentadoria por idade de $70 \%$. No entanto, considerando que a carência para a concessão deste último benefício é, em regra, de 180 contribuições, o patamar mínimo de cálculo do benefício parte de $85 \%$. Neste benefício, a fator previdenciário somente é aplicável nos casos em que gere um acréscimo na renda do trabalhador.
} 
Os benefícios substitutivos da renda sem uma limitação (real ou presumida) para o exercício de atividades laborais, no entanto, escapam à regra da correlação necessidade/proteção. Isto porque a concessão dos benefícios previstos nesta classe assume uma função nitidamente premial, possibilitando a aposentadoria daquele segurado que contribui por determinado período, inexistindo uma necessidade social imediata e aparente.

Além disso, para os benefícios desta classe, o legislador propiciou regramentos distintos das demais, possibilitando a concessão de benefícios com rendimentos proporcionais ${ }^{39}$ à remuneração média do trabalhador.

Até a Emenda Constitucional $n^{\circ} 20 / 98$, por exemplo, a Constituição Federal possibilitava a concessão das aposentadorias proporcionais ao tempo de serviço, em percentual mínimo de $70 \%$ do salário de benefício. Com a extinção desta espécie de benefício, a Emenda constitucional supracitada, estabeleceu regra de transição possibilitando a concessão deste benefício desde que cumprido, além do tempo de serviço mínimo, uma idade mínima e um pedágio. Esta sistemática de cálculo gerou um afastamento considerável entre a média remuneratória do segurado e o valor do benefício.

A partir da publicação de Lei $n^{\circ} 9.876 / 99$ é introduzido no ordenamento jurídico o fator previdenciário, obrigatoriamente aplicado às aposentadorias por tempo de contribuição, que leva em conta, quando da apuração do benefício, a expectativa de sobrevida do segurado, o tempo contributivo e sua idade. Esta sistemática de cálculo pode gerar uma redução na renda do benefício superior a $50 \%$, de acordo com o tempo de contribuição e, principalmente, a idade na data do requerimento.

Analisando-se estes institutos (aposentadoria proporcional, pedágio e fator previdenciário) e os efeitos que eles geram na renda do benefício sob a perspectiva da necessidade social protegida, observa-se que eles se justificam nesta classe de benefícios na medida em que não se vislumbra uma situação de necessidade social no momento da aposentação. Ademais, atualmente, cumprem um importante papel de equilíbrio financeiro e atuarial do sistema.

O grande problema desta "proporcionalidade" da renda destes benefícios está na impossibilidade legal de sua revisão em momento posterior ou, ainda, na impossibilidade de renúncia para fins de pleitear nova benesse.

Com efeito, conforme dispõe o artigo $18 \S 2^{\circ}$ da Lei $n^{\circ} 8.213 / 91$, o aposentado pelo Regime Geral de Previdência Social - RGPS que permanecer em atividade sujeita a este Regime, ou a ele retornar, não fará jus a prestação alguma da Previdência Social em decorrência do exercício desta atividade, exceto ao salário-família e à reabilitação profissional, quando empregado.

Regulamentando a matéria, o artigo 181-B do Decreto $\mathrm{n}^{\circ} 3.048 / 99$ ponta que as aposentadorias por idade, tempo de contribuição e especial

\footnotetext{
${ }^{39}$ No período anterior à Emenda Constitucional n ${ }^{\circ} 20 / 98$, o benefício aposentadoria por tempo de serviço era concedido ao homem com 30 anos de tempo de serviço, e à mulher com 25 anos, sendo o benefício calculado partindo-se de um percentual de $70 \%$ do salário de benefício, acrescendo-se $6 \%$ para cada ano a mais trabalhado.
} 
concedidas pela Previdência Social, na forma deste Regulamento, são irreversíveis e irrenunciáveis.

Atualmente existem grandes discussões judiciais quanto a possibilidade ou não do segurado se desaposentar, bem como a forma que esta se efetivará (com ou sem restituição das parcelas recebidas). Neste estudo, no entanto, pretendemos abordar a questão limitando-nos à análise da função dos benefícios da Previdência Social e a possibilidade de ocorrência de eventos que levem o segurado a se enquadrar em situação de necessidade distinta daquela que deu origem à concessão de seu benefício.

Não há dúvidas que um segurado que se aposenta por tempo de contribuição com a incidência do fator previdenciário, ou de forma proporcional (benefícios substitutivos sem necessidade de comprovação de uma necessidade social, em ambos os casos) pode, no futuro, se enquadrar em outra necessidade, em razão de uma incapacidade total para o trabalho devidamente comprovada ou, ainda, em uma das hipóteses em que o legislador presume a incapacidade ou impossibilidade de trabalho (por exemplo, a idade avançada).

Dentro do sistema jurídico vigente, como exposto, este segurado, ainda que diante de uma nova necessidade (derivada de uma invalidez para o trabalho ou idade avançada, por exemplo) não terá direito a um benefício compatível com esta necessidade, mesmo que preencha os requisitos legais.

A ausência de previsão legal para a revisão do benefício e a impossibilidade de sua renúncia, inegavelmente, fere o princípio constitucional da isonomia, na medida em que trata pessoas que se encontrem diante da mesma situação jurídica de forma distinta.

Além disso, a inexistência de mecanismos legais que possibilitem uma revisão do benefício no caso de o segurado estar diante de uma nova necessidade fere o próprio artigo 201 da Constituição Federal. Isto porque não se ampara adequadamente o segurado que se encontra em uma situação constitucionalmente prevista como objeto de proteção pela Previdência (artigo 201,CF)

Deste modo, há a necessidade de se implementar em nosso ordenamento jurídico mecanismos que possibilitem a alteração de "classe de benefício" quando do surgimento de uma nova situação de necessidade juridicamente relevante e distinta daquela que deu ensejo à concessão do primeiro benefício.

Destaca-se, por fim, que esta revisão, ou concessão de um novo benefício, não fere o princípio constitucional da prévia fonte de custeio, previsto no artigo $195 \S 5^{\circ}$, pois se ampara: a) na própria contribuição vertida ao sistema pelo segurado até então; b) no preenchimento dos requisitos, pelo segurado, do novo benefício; e c) nas contribuições vertidas ao sistema após a primeira aposentadoria. 


\section{Conclusão.}

Como visto, a redução do valor da renda de benefícios substitutivos, de acordo com lógica adotada pelo sistema de cálculo dos benefícios previdenciários, somente se justifica nas hipóteses de benefícios em que não há incapacidade (real ou presumida) ou impossibilidade de exercício de atividades laborais.

Este entendimento justifica a existência de alguns mecanismos calibradores da renda, tal como o fator previdenciário e o pedágio $\left(\mathrm{EC}^{\circ}{ }^{\circ} 20 / 98\right)$ que visam, essencialmente, limitar a concessão de benefícios a segurados de pouca idade.

No entanto, a inexistência de mecanismos que possibilitem a alteração deste benefício em razão de uma nova necessidade social gera grave contradição no sistema; ampara-se situações jurídicas iguais de forma distinta, deixando o segurado em uma situação de insegurança jurídica e econômica diante de uma nova necessidade (invalidez ou idade avançada) que, em tese, ele teria direito caso preenchimento dos requisitos legais para a sua concessão.

Deste modo, no presente estudo buscamos definir um parâmetro para fins de adequação do sistema previdenciário atual, sugerindo uma classificação dos benefícios de acordo com as necessidades sociais objeto de proteção pela Previdência Social, bem como apontando a necessidade de implementação de mecanismos de "troca de classes".

Através deste mecanismo, abre-se a possibilidade de revisão dos benefícios para os segurados aposentados (especialmente aqueles aposentados de forma proporcional ou com aplicação do fator previdenciário) que se enquadrem, no futuro, em uma situação de necessidade social nova (especialmente aquelas derivadas de incapacidade total para o trabalho e idade avançada).

O surgimento de uma nova necessidade social para o segurado, portanto, deve possibilitar uma transformação de seu benefício (seja através de uma revisão ou uma nova concessão, e desde que tenha cumprido os requisitos legais), adequando-o à nova necessidade, em respeito ao princípio constitucional da isonomia e em atendimento ao artigo $201 \mathrm{da} \mathrm{CF}$, que elenca as situações objeto de atendimento específico pela Previdência Social.

Somente assim será possível amparar de forma mais adequada os segurados, oferecendo-lhes benefícios compatíveis com sua necessidade em cada momento de sua vida, e garantir o efetivo cumprimento das funções constitucionalmente previstas da Previdência Social.

\section{Bibliografia}

ALENCAR, Hermes Arrais. Benefícios Previdenciários. $4^{\mathrm{a}}$ ed. São Paulo: Universitária do Direito, 2009. 
Cálculo dos Benefícios Previdenciários. São Paulo: Atlas,

2009.

ALMANSA PASTOR, José Manuel. Derecho de la seguridade social, $7^{\mathrm{a}}$ Ed. Madrid, V I, Editora Tecnos, 1977.

ASSIS, Armando de Oliveira. Compêndio de seguro social. Rio de Janeiro: Fundação Getúlio Vargas, 1963.

BALERA, Wagner. Sistema de Seguridade Social. $3^{\text {a }}$ ed. São Paulo: LTr, 2003.

A Seguridade Social na Constituição Federal de 1988. São

Paulo: Revista dos Tribunais, 1989

; MUSSI, Cristiane Miziara. Direito Previdenciário. São Paulo:

Método, 2008.

BERBEL, Fábio Lopes Vilela. Teoria Geral da Previdência Social. São Paulo:

Quartier Latin, 2005.

BONAVIDES, Paulo. Curso de Direito Constitucional. $11^{\mathrm{a}}$ ed. São Paulo: Malheiros, 2001.

CASTRO, Carlos Alberto Pereira e LAZZARI, João Batista. Manual de Direito Previdenciário. $8^{\text {a }}$ ed. Florianópolis: Conceito Editorial, 2007.

COELHO, Sacha Calmon Navarro (coord). Contribuições para a Seguridade Social. São Paulo: Quartier Latin, 2007.

DÁVALOS, José. La Crisis de Los Sistemas de Seguridad Social. Fonte: www.bibliojuridica.org/libros/2/642/5.pdf Acessado em 24/08/2011.

DELGADO. Ignácio Godinho. Previdência Social e mercado no Brasil. São Paulo: Ltr, 2001.

DERZI, Heloisa Hernandez. Os benefícios da pensão por morte: regime geral de previdência social. São Paulo: Lex Editora, 2004

HORVATH Júnior, Miguel. Direito Previdenciário, $7^{\text {a }}$ ed. São Paulo: Quartier latin, 2008.

IBRAHIM, Fábio Zambitte. Curso de Direito Previdenciário. 11 ${ }^{\text {a }}$ Ed. Niterói: Impetus, 2008

KONKEL Júnior, Nicolau. Contribuições Sociais. São Paulo: Quartier Latin, 2005 .

LEITE. Celso Barroso. A proteção Social no Brasil. São Paulo: Ltr, 1972.

LIGERO, Maria de los Santos Alonso. Los Servicios Sociales y la Seguridad Social, Volume n. ${ }^{\circ}$ 6. Revista Ibero-americana de Seguridad Social.1971.

LUHMANN, Nickas. Sociologia del Riesgo. México: Universidad Iberoamericana, 2006.

MARTINEZ, Wladimir Novaes. Curso de Direito Previdenciário, Tomo II, $2^{\mathrm{a}}$ Ed. São Paulo: Ltr, 2003

Comentários à Lei Básica da Previdência Social, Tomo

II, $4^{\text {a }}$ Ed. São Paulo: Ltr, 1997

MEDEIROS, Marcelo. A Trajetória do Welfare State no Brasil: Papel Redistributivo das Políticas Sociais dos Anos 1930 aos Anos 1990. Fonte: http://www.ipea.gov.br/pub/td/td_2001/td_0852.pdf 
PAULSEN, Leandro. Contribuições - Custeio da Seguridade Social. Porto Alegre: Livraria do Advogado, 2007

PERSIANI, Mattia. Direito da Previdência Social. São Paulo: Quartier Latin, 2009.

ROCHA, Daniel Machado da; SAVARIS, José Antonio.(coordenadores). Curso de Especialização em Direito Previdenciário. Curitiba: Juruá, 2008;

ROCHA, Daniel Machado da. O direito fundamental à Previdência Social. Porto Alegre: Livraria do Advogado, 2004

RUSSOMANO, Mozart Victor. Curso de Previdência Social. $2^{\text {a }}$ Ed. Rio de Janeiro: Forense, 1983.

Recebido em 03-10-2011

Avaliado em 03-11-2011

Aprovado para publicação em 05-12-2011 